\title{
On the use of hand-held X-ray fluorescence spectroscopy coupled to Monte Carlo simulations for the depth assessment of painted objects: The case study of a sixteenth-century illuminated printed book
}

\author{
Silvia Bottura-Scardina ${ }^{1,2,3,4} \mathbb{D}$, Antonio Brunetti ${ }^{5}$, Carlo Bottaini ${ }^{1,6}{ }_{(\mathbb{D}}$, \\ Catarina Miguel $^{1,6, \mathrm{a}_{(\mathbb{D}}}$ \\ ${ }^{1}$ HERCULES Laboratory, University of Évora, Palácio do Vimioso, Largo Marquês de Marialva 8, \\ 7000-809 Évora, Portugal \\ 2 Centro de Investigação e de Estudos em Belas-Artes (CIEBA), University of Lisbon, Largo da Academia \\ Nacional de Belas Artes 4, 1249-058 Lisboa, Portugal \\ 3 Centro Interdisciplinar de História, Culturas e Sociedades (CIDEHUS), University of Évora, Largo do \\ Marquês de Marialva 8, Palácio do Vimioso, 7000-809 Évora, Portugal \\ 4 Consortium HERITAS - Estudos de Património, University of Évora, Évora, Portugal \\ 5 Dipartimento di Chimica e Farmacia, University of Sassari, Via Vienna 2, 07100 Sassari, Italy \\ ${ }^{6}$ City University of Macau Chair in Sustainable Heritage, Universidade de Évora, Largo dos Colegiais 2 , \\ 7000-645 Évora, Portugal
}

\begin{abstract}
This paper presents the application of an established XRF-MC (X-ray fluorescenceMonte Carlo) protocol to evaluate for the first time the thickness of pictorial layers in illuminated manuscripts. A previously investigated, sixteenth-century book printed in Paris (BPE, Inc. 438) was chosen as the case study: multiple analysis spots were scanned in selected areas (painted and unpainted) with p-XRF (hand-held XRF); later, the obtained spectra were compared against Monte Carlo simulations. Two pathways of MC simulations emerged: a three-layer model for the painted areas (stratigraphic sequence, from outer to inner: pictorial layer-underdrawing-parchment) and a two-layer model for the unpainted areas (underdrawing-parchment). Also, the calculated thickness of each simulated layer was compared against the thickness of micro-samples from Inc. 438. The results proved the protocol to provide quantitative compositional and stratigraphic data, yet with limitations. Results encourage the future research to elaborate a protocol.
\end{abstract}

\section{Introduction}

Determining the stratigraphic succession and structure of pictorial layers is a routine practice in painted artworks analysis. Because polychrome surfaces comprise consecutive applications of preparatory layers, paint layers and varnish, retrieving such information allows getting insights into the creative process that artists followed to produce the desired visual effects.

\footnotetext{
a e-mail: cpm@uevora.pt (corresponding author)
} 
How an overlaid painted surface appears, both as for texturing and colouring, depends on a profound mastery of the ultimate display of colourant mixtures next to a skilful manipulation and use of art materials [1]. Therefore, a global mapping of pictorial multi-layer becomes critical to reveal useful information to identify and describe the process that an artist followed to create the object turning into a guide to their work [2]. A paint stratigraphy can unveil an object authenticity, attribution, but can also expose ongoing processes of material degradation. With stratigraphic analyses, past investigations described the state of conservation of polychromatic works $[3,4]$. As traditionally conducted, the analysis of pictorial stratigraphies is a multi-step workflow that includes micro-sampling, cross sections preparation followed by their characterisation with high-resolution and micro-analytical techniques $[5,6]$. However, this conventional approach destructs the integrity of the painting, and its application in illuminated books study is unsafe because of two major hazards. Depictive layers in book heritage are too thin to permit suitable preparation of cross sections [7], and pictorial films create a robust system with the parchment ground, so the harm of this practice is more severe for this class of art objects. As a result, stratigraphy characterisation is still tentative in illuminated books studies.

Because of the need for non-invasiveness, previous researches explored the potential of non-invasive approaches: p-XRF (portable energy-dispersive X-ray fluorescence spectroscopy) has proved to be a powerful technique because it does not bring the constraints relative to sample preparation while providing a fast elemental profile of an analysed object $[8,9]$. Therefore, XRF combined with Vis-RS (visible-reflectance spectroscopy) could determine the paint's thickness of painted artworks [10,11], or p-XRF alone tested specific lines$\mathrm{Pb}-\mathrm{L} \alpha, \mathrm{L} \beta$, as attenuated by the Au layer of golden foils used in illuminated manuscripts [12]. Another class of methods embeds MC (Monte Carlo) algorithms coupled to spectroscopic results to simulate the micro-structure of polychromatic multi-layers. This class of methods computes a probabilistic simulation of a phenomenon of interest; when applied to spectroscopy, it simulates radiation-matter interactions. Due to its versatility, a fair number of MC code systems have been developed [13-28]. A part of those codes focused on the interactions between low-energy X-rays and matter, resulting in such specialised and fast MC codes for XRF as XMI-SIMS [24-26] and XRMC [27,28]. These two latter systems employ the same class of algorithms and library of X-ray phenomena, Xraylib [29], while maintaining comparable performances [30].

A case of the application of XMI-SIMS was in non-invasive, in situ stratigraphic study of metallic thin and thicker mono-layered coatings [31]; among other, XRMC was applied to determine the composition of archaeological objects: decorated pottery [32], as well as mono- or bi-layers of corrosion surfaces in metal artefacts [33-36].

Painted objects were also studied: such is the case of thickness of metallic mono-layered coatings applied to panel paintings, like gildings [37]. Some of the cited methods employed p-XRF systems, but also the most recent XRF scanning (macro-X-ray fluorescence, MA$\mathrm{XRF}$ ), that have become popular in paintings examinations for authentication and material distribution studies [38-43]. Speaking of MA-XRF, MC codes was also applied to scanning systems to investigate specific layers of interest in paintings $[44,45]$. However, the greatest efforts in the coupling of MC methods and XRF were spent to study the composition of metallic layers in easel paintings, like the mentioned gold leaves; instead, this is not the case for other components of painted objects or other classes of objects.

Illuminated books are another important class of painted artworks. Despite their general interest in material characterisation for the identification of the artistic palettes [46-48], and XRF characterisation of inks [49-53], researches did not venture into the coupling of MC simulations to XRF to date. A cause for this lack of interest is in the perils that XRF offers 
in stratigraphic studies of books, especially regarding the high proportion of low-Z elements of the substrate (either paper or parchment), which do not produce significant fluorescence lines despite of contributing to the background of XRF spectra. This physical limitation leads to a general disregard, that adds to the complexity of paints micro-structure: illuminations consists roughly of uneven coatings of inorganic and organic materials such as polysaccharide and protein organic binders, found alone or as an admixture of both, fillers (calcium sulphides/carbonates at several degrees of purity), natural or synthetic pigments (minerals) and organic lakes (precipitates of vegetable or animal juices complexed with transition metals). Also, parchment, namely the organic ground of medieval and early Renaissance books, gives a poor response to the X-ray radiation, making it partly unsuitable for such analyses. Therefore, these objects are chiefly organic, resulting in the need for bespoke methodologies.

\section{Materials and methods}

The validity of the use of the XRF-MC protocol for the study of illuminated books was assessed on a case study, Inc. 438. Figure 1 summarises the adopted workflow.

A major illumination from the book on fol.1r (Printer's device) was chosen for the evaluation of the thickness of each pictorial layer-inferior, printing ink layer; superior, coloured layer. Multiple XRF spectra were acquired from each coloured area-red, green, blue (hereafter painted areas) and from areas where the printing ink was exposed (hereafter unpainted areas). The unpainted areas correspond to regions where the printing ink of the initial engraving (hereafter underdrawing) directly covers parts of the parchment ground while the coloured layers are superimposed to the engraved image. The reliability of each assay for the MC simulation was determined with MATLAB software, which extracted and elaborated colourthresholdings from images of the XRF analysis spot to express each as percentages of the overall analytical areas. The XRMC (X-ray Monte Carlo) program was employed to build simulations of the XRF spectra. The comparison of the similarity between the measurements and the simulation was achieved visually.

\subsection{Applying the MC-XRF approach to illuminated incunabula}

The application of the MC-XRF protocol to painted books was subjected to several requirements and limitations. About the requisites, p-XRF was reckoned as desirable due to its versatility and power to yield useful data on the elemental profiles of art objects. In illuminated books studies, these two conditions already allowed its successful application because of its twofold capability of providing reliable results in a short time as a non-destructive, in situ technique and to reach the deep levels of pictorial coatings.

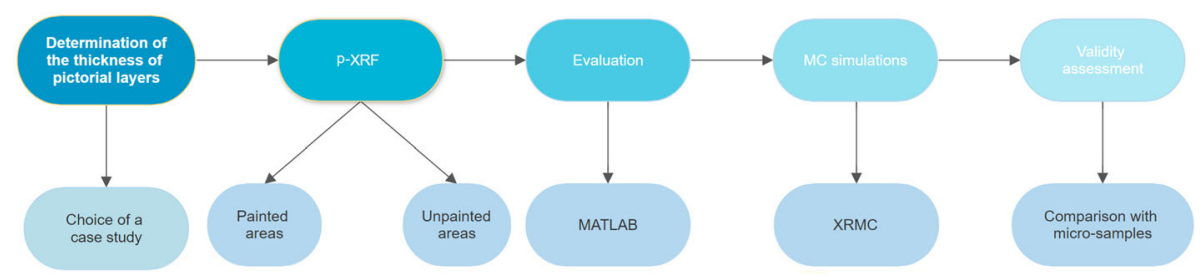

Fig. 1 Experimental design followed in the study of the thickness assessment of a representative illustration from Inc. 438 
Despite of its analytical potential, the MC-XRF protocol to painted book presented, however, a number of factors challenged its full potential. A major physical limitation consisted in the fact that illuminated decorations are complicated pictorial systems consisting of multilayers applied directly on an organic substrate, that is parchment in this case. This overall statement summarises the simultaneous influence of several factors, starting from the substrate composition until the pictorial anatomy and constitutive elements. As for the parchment substrate, the first limitation consists in its organic nature. Because organic elements are mostly made of light elements, the protocol is theoretically and practically affected: in the first place, the detectors of portable XRF analysers fail to determine analytes with $\mathrm{Z}<11$ $(<\mathrm{Na})$, while their sensitivity to light elements $(\mathrm{Mg}$ to $\mathrm{P})$ is limited and largely dependant on the geometry configuration of the device/type of matrix - that is to say, when their concentrations are adequate or do not approximate lower detection limits and the detection is aided by a vacuum. Then, organic materials pose a critical problem to quantitative $\mathrm{p}$-XRF analyses because the elements that constitute the parchment background are not directly determined and contribute significantly to the Matrix Effect of these spectra.

Not only the substrate, but also the crafting technique itself might pose important obstacles. Illuminated decorations are systems consisting of a complicated micro-structure of thin heterogeneous layers, regarding analyte concentration and local distribution in a layer, uneven stratigraphic succession or differentiated treatment of individual pigments: just to provide an instance for the last case, vermilion was occasionally mixed with little saffron [54], or dye colourants were preferably incorporated to proteinaceous binders rather than natural gums also in decorations mostly formulated with the latter. Therefore, the sum of these factors together made the detection of individual pictorial layers a challenging task.

Other possible limitations did not apply merely to illuminated books, rather to the fact of observing printed books for investigation. For this research aimed to consider the technique as applied to incunabula, the technical specificity of these objects must have been taken into account. Book leaves were double-side printed so the heavier elements of the text ink might be visible (because of the low absorption of $\mathrm{C}$ and lighter elements, which can be measured through their mass absorption coefficients). Additionally, the organic elements of the text ink might add to the Matrix Effects from parchment.

Finally, the selection of BPE, Inc. 438 as the appropriate case study for this method was driven by other practical facts: because several paints of the object have been already studied (fols. 8r, 11r, 47v, 61v, 65r), the number of possible variables that might have come into play (number of layers, micro-structural complexity, heterogeneous multi-layers and so forth) was already known. The technical familiarity with this incunabulum granted the necessary knowledge to regard it as a relatively simplified case (as far as incunabula paintings can be); also, the broadest pictorial areas and large unpainted areas in fol. 1r were elected as the spot of analysis. Hence, working on a known case study had the purpose of verifying the reliability of the proposed method.

\subsection{The book: BPE, Inc. 438}

The item selected for the study is a Book of Hours, or a book of prayers, held by the Public Library of Évora-Portugal (Fig. 2). Produced by the Parisian printer Germain Hardouyn, a printer-publisher and illuminator registered in Paris $[55,56]$ who specialised in producing luxury prayer books between the late 1490s and the 1550s, sometimes supplying them with bespoke illumination under special request of individual clients [57,58]. The proposed date for the book publication is c. 1528 [59], and the analysed picture features the device of Germain Hardouyn, which represents in full-page a figurative design specific to his own 
Fig. 2 Full-size image of the selected folium from Inc. 438 (170 mm x $103 \mathrm{~mm}$ ) containing the representative illumination, the Printer's device (92 mm x 61 mm, fol. 1r). Photo (C) HERCULES Lab and BPE

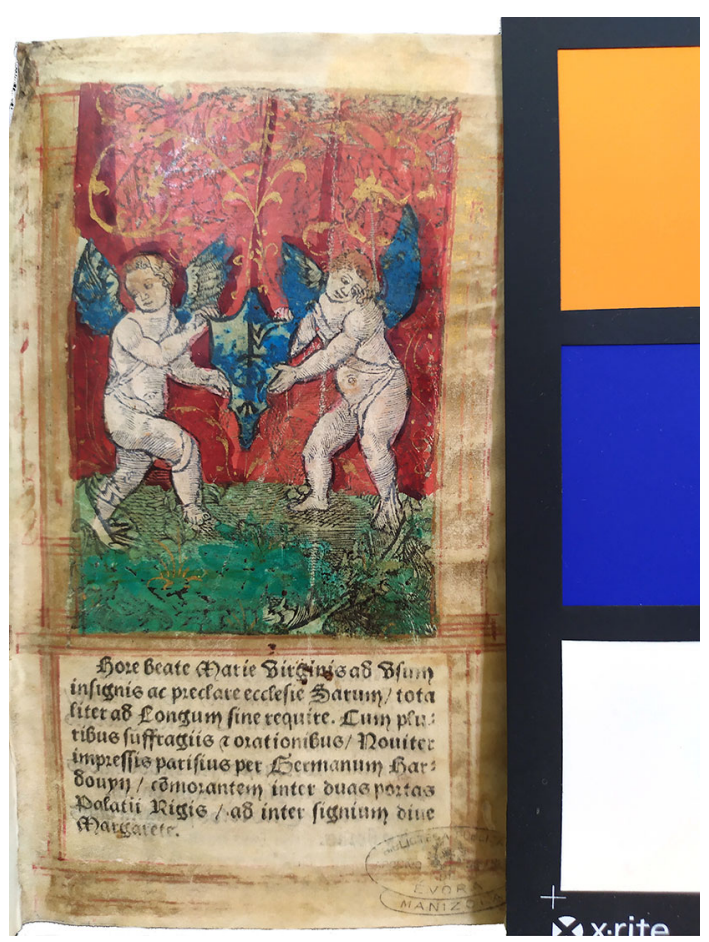

printing firm and in use since c. $1524[60,61]$. This characteristic representation pictures two cupids supporting a shield with the initials of the producer "GH" drawn in elaborate style. Painted in three colours-red, blue and green, the image is set in architectonic gold frames with trailing cords and tassels and locates at the frontispiece of the book, just above the book title. Through the paint, the laurel wreath embedding the two angels in the uncovered representation disappears to accommodate a lawn and an undefined red background, most likely a curtain.

This image was selected from the whole set of illuminated decorations because it responded the most successfully to the double requirements of offering broad pictorial areas and relatively large unpainted areas. In the second case, the uncovered areas corresponded to regions where the painted layer flaked away, with the result of exposing the under-laying model design.

Two spots for each of the three coloured areas were analysed by p-XRF plus three supplementary spots for the unpainted areas (Fig. 3). The first group of spots corresponding to the painted areas is identified with the numbers 1-6 (coloured circles) while the rest goes under the numbers 1-3 (white circles). The parchment background from three other leaves throughout the book (fols. 11r, 47v, 65v) of the same item was further used to calibrate the spectra on the average substrate elemental profile. The composition of the printing ink from this leaf was compared to micro-samples collected from other leaves during a previous investigation of the same book (fols. 11r, 47v). 
Fig. 3 Maps of the analysed coloured areas in Printer's device (fol.1r). The red circles represent the red p-XRF analysis spots (numbers 1,2), the blue circles the blue p-XRF analysis spots ( 3 , 4) while the green circles the green p-XRF analysis spots (5, $6)$. The white circles represent the unpainted $\mathrm{p}-\mathrm{XRF}$ analysis spots (1-3). Photo @HERCULES Lab and BPE

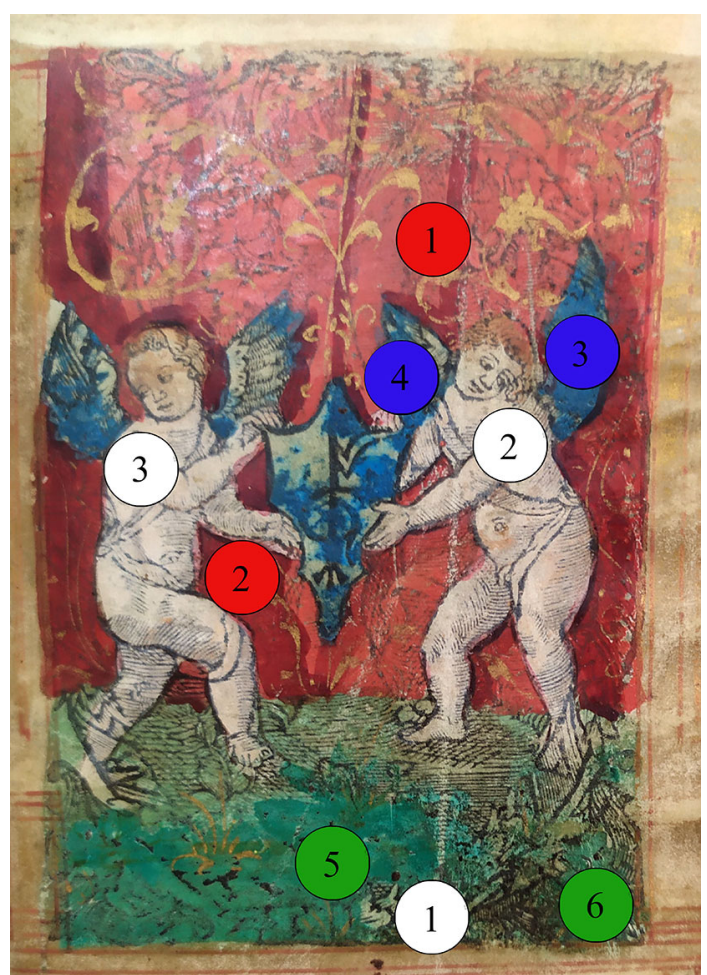

\subsection{Artistic technique}

The initial image appears as a print realised with an engraving technique, either woodcutting or metal-cutting $[58,62]$. Serving as a model for later handmade decoration, single or few applications of opaque layers of paint cover the initial print generally along the lines of the original engraved design.

The palette, as previously characterised, includes the red pigments vermilion $(\alpha-\mathrm{HgS}$, mercury sulphide) and minium $\left(\mathrm{Pb}_{3} \mathrm{O}_{4}\right.$, lead oxide), the blue pigment azurite $\left(2 \mathrm{CuCO}_{3}\right.$. $\mathrm{Cu}(\mathrm{OH})_{2}$, basic copper carbonate), the green pigment malachite $\left(\mathrm{CuCO}_{3} \cdot \mathrm{Cu}(\mathrm{OH})_{2}\right.$, acid copper carbonate) mixed with the yellow pigment lead tin yellow I $\left(\mathrm{Pb}_{2} \mathrm{SnO}_{4}\right)$; gold shell (powder gold mixed to a binder) applications cover parts of the image as the finishing touch. A polysaccharide substance could be the medium, with chalk often mixed as an extender [63]. Contrary to what is traditionally observed in illuminations, the great majority of the coloured coatings in Inc. 438 are mono- or bi-layers of paints, with further levels containing lead white $\left(2 \mathrm{PbCO}_{3} \cdot \mathrm{Pb}(\mathrm{OH})_{2}\right.$, basic lead carbonate) added as a scattering pigment to add brightness whenever necessary, or brown ochre to darken [64].

\subsection{P-XRF and Monte Carlo simulation}

The analyses were performed with a Bruker Tracer III-SD hand-held p-XRF spectrometer equipped with a Rh tube and a Peltier-cooled Si drift operating at $40 \mathrm{keV}$, and an internal VGA CMOS camera for photo acquisition of the analysis spot. The operating conditions were decided following those already applied in the analysis of illuminated books [63,65]: 4.50 
$\mu \mathrm{A}$, no filter, $120 \mathrm{~s}$ acquisition time and acquiring spot $12 \mathrm{~mm}^{2}(3 \mathrm{x} 4 \mathrm{~mm})$ for the analysis of the paint, and $12.50 \mu \mathrm{A}$, no filter, $90 \mathrm{~s}$ acquisition time and acquiring spot $12 \mathrm{~mm}^{2}(3 \mathrm{x}$ $4 \mathrm{~mm}$ ) for the analysis of the parchment primer. In all analyses the device was mounted on a tripod and placed at a working distance of semi-contact (maximum 2-3 mm away) with the analysed surface. The spectra acquisition was performed with S1PXRF software while shootings of the analysed spots were done with CyberLink YouCam software for the online view with the spectrometer built-in camera ( $400 \times 400$ pixels resolution).

The current version of the code of the XRMC program for the elaboration of the MC simulations was developed in a collaboration between Ghent University, the European Synchrotron Radiation Facility and University of Sassari [27,28]. It is based on the database for X-ray interactions Xraylib [29,66] and has been implemented for the analysis of rough surfaces. The special version of XRMC used here has been developed for rough surfaces of corrosion layers of archaeological artefacts, this feature came in handy for the analysis of paints on manuscripts, which can be seriously affected by the geometric factor of local areas of undulation typical of animal skin sheets. XRMC simulates the detector response to the incoming X-ray radiation based on the model of the spectrum emitted by the X-ray source, the response of the detector and its efficiency, the convenient experimental set-up and a user-defined quantification of the component of the analysed area at a given configuration [67].

The influence of the surface topography was studied under microscope and the obtained values were expressed as average height. The microscopical inspection allowed us to determine an overall roughness between 10 and 16 micron ( \pm 5 micron), meant as the average difference of the absolute difference of level between an ideal plane and the lowest/highest points of the cross-profile. Also, during the same analyses, we could assess an average of valleys amplitude measuring around $1 \mathrm{~mm}$. Based on these data, we performed several attempts to match the best fit for the simulation of the real surface using models simulating various distributions of surface irregularities-from sinusoidal models with spatial period corresponding to the assessed value of roughness and random noise-until flat surfaces. These attempts show that no observable differences between the simulated spectra. For this reason, a simple flat surface has been selected as the standard model for the simulated samples. In all likelihood, the design of the portable analyser and the mounting setting were such that the intensities of X-ray radiation emerging from the rough surfaces of the analysis spot of BPE, Inc. 438 were comparable to a flat surface's response. In addition, the large size of the spot of analysis (approx. $12 \mathrm{~mm}^{2}$ ) had the effect of averaging the information about local irregularities. For these reasons, we considered adopting a flat plane for the simulations a sensible choice.

Margin of uncertainty for the chemical composition of these assays is $10 \%$ for all elements.

\subsection{MATLAB area analysis}

To evaluate the suitability of the spots for the MC simulations, shootings recorded with

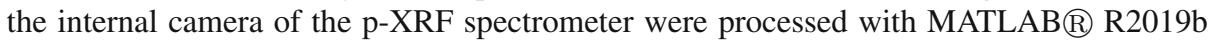
software with Image Processing Toolbox ${ }^{\mathrm{TM}}$ 11.0, Colour Threshold App to extract colour maps. A first map of the overall area of the spot was used as the first comparing quantity, while the areas corresponding to individual coloured areas or inked areas were mapped separately as the second comparing quantity. Both the overall area of the spot and the coloured areas were later converted to binary masks and percentages of the images were calculated and expressed as percentages of the overall area under analysis. The spots with the largest area 
Table 1 Results of the evaluation of the coverage assessment for each pictorial layer

\begin{tabular}{lllll}
\hline Spot & & Component & Amount $(\%)$ & Error (\%) \\
\hline 1 & Red paint 1 & Red paint & 89.2 & 0.4 \\
2 & Red paint 2 & Red paint & 60.6 & 0.4 \\
3 & Blue paint 1 & Blue paint & 63.8 & 0.4 \\
& & Red paint & 19.3 & 0.2 \\
4 & Blue paint 2 & Blue paint & 49.3 & 0.3 \\
& & Red paint & 4.2 & 0.1 \\
& & Ink & 6.6 & 0.1 \\
5 & Green paint 1 & Green paint & 77.6 & 0.4 \\
& & Ink & 1.2 & 0.1 \\
6 & Green paint 2 & Green paint & 54.4 & 0.4 \\
& & Ink & 17.8 & 0.2 \\
No paint 1 & Printing ink 1 & - & - & - \\
No paint 2 & Printing ink 2 & Ink & 43.9 & 0.3 \\
No paint 3 & Printing ink 3 & Ink & 30.2 & 0.3 \\
\hline
\end{tabular}

Confidence interval is expressed as standard deviation $(1 \sigma)$ of the binary image produced for each pictorial component

Table 2 Quantitative EDS analysis of the printing ink expressed in normalised counts (left column), with quantification based on the $\mathrm{K}$-series lines of the mentioned elements (except for $\mathrm{Pb}$, for which the $\mathrm{L}$-series lines were used)

\begin{tabular}{lcl}
\hline Element & Norm. counts $(\%)$ & Error $(\mathrm{wt} \%)$ \\
\hline $\mathrm{Na}$ & 3.4 & 0.1 \\
$\mathrm{Al}$ & 2.3 & 0.1 \\
$\mathrm{Si}$ & 2.1 & 0.1 \\
$\mathrm{P}$ & 2.4 & 0.1 \\
$\mathrm{Ca}$ & 38.1 & 0.5 \\
$\mathrm{Cu}$ & 11.8 & 0.2 \\
$\mathrm{~Pb}$ & 40.0 & 0.7 \\
\hline
\end{tabular}

Confidence interval is expressed as standard deviation $(1 \sigma)$ of the atomic weight (wt $\%$ )

of individual paints were used as the reference for the MC simulation for the colourant (Table 1).

\subsection{Other techniques}

The conditions used for the Vis documentation, $\mu$-Raman, $\mu$-FTIR, SEM-EDS analysis of the paints and the inks for printing the image are as specified in previous works $[63,64]$. Although the paper is concerned mainly with p-XRF analysis and Monte Carlo simulations, the results for the printing inks and paints from other leaves of the same manuscript (fols. 11r and $47 \mathrm{v}$ ) are from previous characterisations following a multi-analytical approach. In order to support the following discussion of the results of this study, these past data are presented as a reference of comparison. 


\section{Results and discussion}

\subsection{X-ray fluorescence spectrometry analyses}

The two XRF spectra of the red paints look comparable to each other (Fig. 6): both display the peak of line $\mathrm{Hg}-\mathrm{L} \alpha$, as the most prominent, whereas other emerging elements are mercury, lead and copper-which are revealed with the lines $\mathrm{Hg}-\mathrm{L} \alpha,-\mathrm{L} \beta, \mathrm{Pb}-\mathrm{L} \alpha,-\mathrm{L} \beta$ and $\mathrm{Cu}-\mathrm{K} \alpha . \mathrm{Pb}-$ $\mathrm{M} \alpha$, because of its potential fusion with the lines $\mathrm{Hg}-\mathrm{M} \alpha$, and $\mathrm{S}-\mathrm{K} \alpha$, made the identification of $\mathrm{S}$ less straightforward. The major difference between the two assays is that the XRF spectrum of the second area (point 2) appears visibly richer in lead but despite the difference, both areas are likely to include vermilion as the red pigment.

The same observations as the red paints apply to the blue paint where a single peak emerges, and the two assays provide comparable results. However, the $\mathrm{Cu}-\mathrm{K} \alpha$, and $\mathrm{Cu}-\mathrm{K} \beta$ lines evidence copper as the major element, while lead is still visible yet to a much inferior extent than the former. Being so pronounced, the richness in copper can substantiate the use of azurite as the blue pigment for the illumination under investigation.

Both XRF spectra reveal copper as the major element through the $\mathrm{Cu}-\mathrm{K} \alpha, \mathrm{Cu}-\mathrm{K} \beta$-lines. However, there is a non-negligible signal from the Pb-L $\alpha, \mathrm{Pb}-\mathrm{L} \beta, \mathrm{Sn}-\mathrm{K} \alpha, \mathrm{Sn}-\mathrm{K} \beta$ and $\mathrm{Sn}-$ $\mathrm{L} \beta$-lines, which support the use of a mixture of malachite and lead tin yellow as previously investigated.

\subsection{Printing ink composition}

The results of this study were compared with the SEM-EDS and $\mu$-FTIR results from microsamples of the printing inks of other leaves (fols. 11r, 47v) collected from BPE, Inc. 438 during a past (unpublished) research. According to EDS analysis (Table 2), two distinct areas appear, one enriched in copper and lead while the other is intensive in phosphorus, calcium and other light elements- Na, Si, Al. SEM analysis showed that the specific micro-structure of the $\mathrm{P}$ and Ca-rich area consisted of amorphous crystals with lamellar-to-angular shape of microscopic size, with round nano-metric particles clustered on the surface of the larger crystals (Fig. 4). The two conditions of abundance of calcium and phosphorus and the specific micro-configuration are compatible with hydroxyapatite $\left(\mathrm{Ca}_{10}\left(\mathrm{PO}_{4}\right)_{6}(\mathrm{OH})_{2}\right)$, the inorganic component of bone black pigment [68]. The IR spectrum of representative micro-samples displays bands at 1450, 1417 and $875 \mathrm{~cm}^{-1}$ (Fig. 5), which also belong to carbonated hydroxyapatite [69]. However, three strong bands centred at 1658, 1550, $1230 \mathrm{~cm}^{-1}$, respectively, attributed to the amide $\mathrm{I}$ (peptide $\mathrm{C}=\mathrm{O}$ stretching vibration, weakly coupled with $\mathrm{C}-\mathrm{N}$ stretch and $\mathrm{N}-\mathrm{H}$ bending), amide II (combination of the $\mathrm{C}-\mathrm{N}$ stretch strongly coupled to $\mathrm{N}-\mathrm{H}$ inplane bending modes) and amide III vibrations ( $\mathrm{N}-\mathrm{H}$ in-plane bending coupled to $\mathrm{C}-\mathrm{N}$ stretch with $\mathrm{C}-\mathrm{H}$ and $\mathrm{N}-\mathrm{H}$ deformations) [70,71], may belong to residual collagen. Some studies on bone tissue and bone-based materials assign it to bone tissue residuals surviving the combustion $[68,72]$ and would further support the identification of this carbon-based pigment. However, it is also equally probable that collagen might not belong to the pigment. In the process of separating a small portion of ink from the ground as the micro-sample, extreme attention was paid in ensuring to remove only the desired material. Nevertheless, a minimal portion of collagen from the parchment sheet may have been collected as well. As the result, this minimal parchment portion could act as a contaminant to the IR spectrum, reinforcing the amide vibrations of the collagen moieties.

Although sharp, the three IR bands of the amides can also bring information of further components. The broad peak at $3346 \mathrm{~cm}^{-1}$ belongs to the stretching vibration of hydroper- 


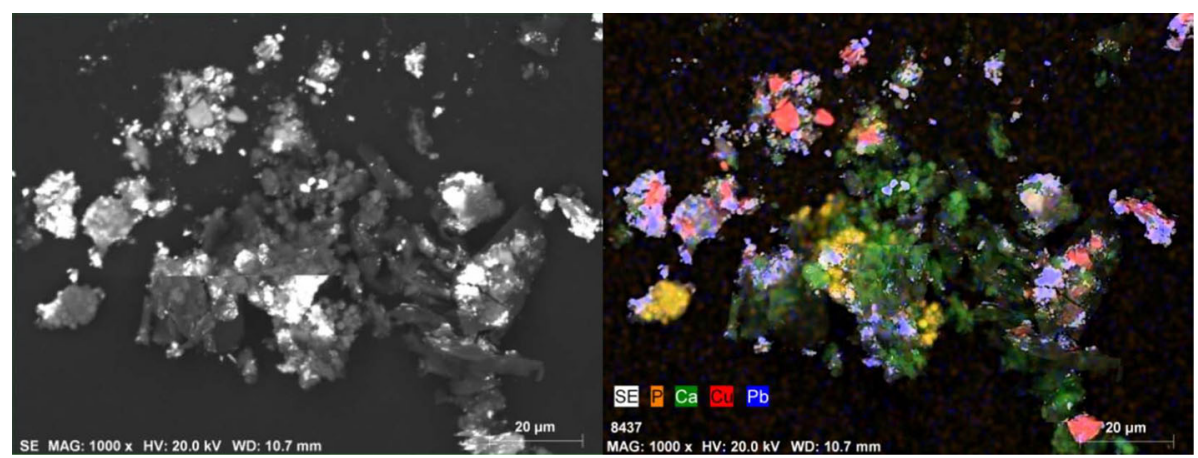

Fig. 4 SEM images of the printing inks at 1000x magnification. From left to right: SE image of a microsample from a leaf of Inc. 438 (fol. 47v), SE-EDS image of the micro-sample displaying data of P, Ca, Cu and $\mathrm{Pb}$. Photo $\mathrm{CHERCULES} \mathrm{Lab}$

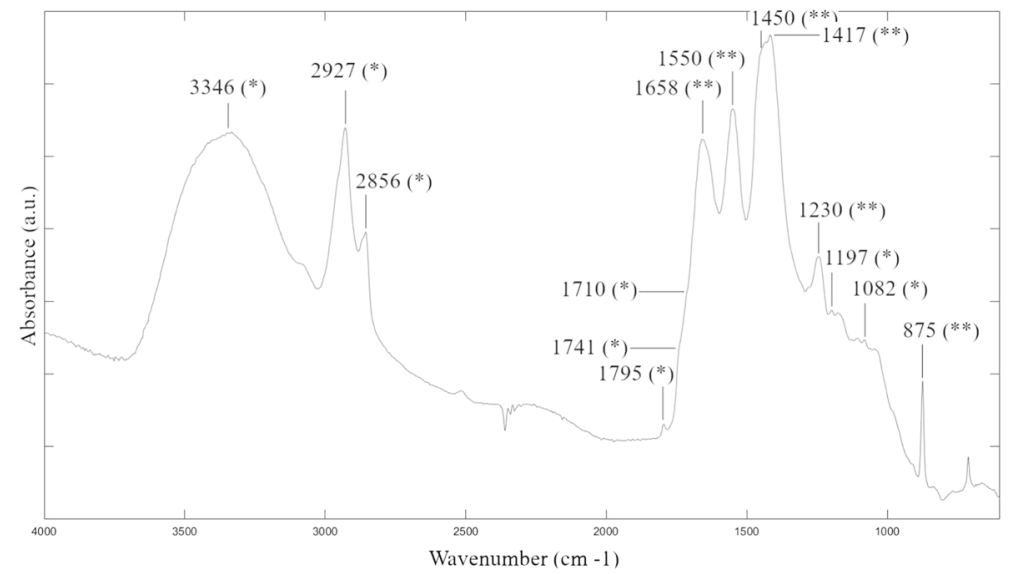

Fig. $5 \mu$-FTIR spectrum of the printing ink, evidencing the IR bands characteristic of the oil binder (*) and of the bone pigment $(* *)$

oxides [73]; together with the very weak vibrations at $2965 \mathrm{~cm}^{-1}$ (stretching of the methyl), the peaks at 2927 and $2856 \mathrm{~cm}^{-1}$ (asymmetric and symmetric stretching of the methylene) [74-78]. In the region between 1800 and $1680 \mathrm{~cm}^{-1}$, a series of complicated, weak vibrations broaden the base of the next peak centred at $1658 \mathrm{~cm}^{-1}$ — that are 1795 [74], 1741 [73-75,7779] and $1710 \mathrm{~cm}^{-1}$ [74] - are stretching of $\mathrm{C}=\mathrm{O}$ functional group. At lower wavenumbers, a series of vibrations, namely 1197 [76], 1170 [80], $1082 \mathrm{~cm}^{-1}$ [76], are the stretching modes of C-O. All these vibrations have been observed to belong to drying oil binder IR spectra, where the last two groups falling in the regions $1800-1680 \mathrm{~cm}^{-1}$ and $1200-1080 \mathrm{~cm}^{-1}$ is related to the formation of secondary oxidation products, ester and triglyceride ester linkage as part of the curing reaction of drying oils [81].

Being triacylglycerides employed as the vehicle, the printing ink of Inc. 438 could be an oil-based medium, in agreement which result agrees with the information reported in other sixteenth-century recipes and documents $[82,83]$. A part of the historical recipes recommends adding rosin to the compound; unfortunately, the area that fingerprints its presence (the region falling in the range $1800-1680 \mathrm{~cm}^{-1}$ [84]) offers no visible trace. 
Copper and lead from EDS analysis could not be detected from the IR spectrum. Nonetheless, their presence is compatible with previous observations on early typographic inks $[85,86]$. Some of these studies on the preparation of historical drying oils for painting described the intentional supplementing of metal compounds either as solubilised in boiling oils or added to cold oils [87]: transition metals act as catalysing agents of the crosspolymerisation process that enables a liquid oil to evolve into a semi-solid, flexible film (curing process) at a much enhanced rate than without [88]. Early workers found that in the range 1.0-2.0\% metal per oil (wt), lead compounds performed the best [87].

\subsection{Monte Carlo simulations}

XRMC modelled two patterns of MC simulation for the paints of Inc. 438 (Fig. 6). One of which is a two-layer model for the unpainted areas, the other is a three-layer model for the painted areas. Through MATLAB mappings, the point 1 (red paint 1) was chosen as the reference to calibrate all simulations because it offered the broadest region of coloured paint without the influence from neighbouring areas. Despite of realising two acquisitions for each colour paints, only one spot for each colour paint could serve satisfactorily the present study by overall coverage of the paint within. As a result, a total of three simulations is presented, one for each colour (one for the red paint, one for the blue paint and another one for the green paint); Monte Carlo simulations were built for all the unpainted spots under investigation (for a total of three analysis spots).

The reference model used as initial guess model for XRMC was calibrated on a 1:6 pigment-to-binder (P/M) ratio $(20 \% \mathrm{HgS}$ in polysaccharide binder, dry \%wt) for the outer layer (red paint), a 1:1 P/M ratio for the printing ink (50\% black pigment in drying oil) and a given thickness of $1 \mathrm{~mm}$ for the parchment. The choice for the proposed concentration of red pigment in the binder was based on previous studies of illumination paints composition [89], while the amount of black pigment in the alkyd binder was set to the limit of the accepted concentrations of an oil-based carrier phase, 30-50\% [90]. XRMC determined initially an average level of $20 \mu \mathrm{m}$ thickness for the first layer and $40 \mu \mathrm{m}$ for the second on the simulated spectra. Each layer was assumed as homogeneous and even for the calculation.

The simulated spectra background could not provide a good fitting with the background of the measured spectrum at low energies. This is mainly due to the influence of the electronic noise of the detector which produce a background cannot be attributed to the excitation spectrum emitted from the X-Ray tube [91]. Despite the limitation, the peaks of the major elements-such as $\mathrm{Ca}, \mathrm{Fe}, \mathrm{Cu}, \mathrm{Hg}, \mathrm{Pb}$ - and the background from $5 \mathrm{keV}$ onwards generally conformed to the real measurements. In addition, $\mathrm{MC}$ simulations provided a better fit when lead and copper were assigned to the printing ink layer beneath together. Calcium had to be assigned to all ink layers in the three-layer models for the paints; little mercury had to be assigned to the ink layer of point 1 simulation.

The same level of thickness was calculated in the remaining assays. The XRMC spectra could simulate for the blue and green spots spectra matching the simulations in a similar way as the red one.

All unpainted areas show a similar profile: $\mathrm{Cu}, \mathrm{Pb}, \mathrm{Fe}$ appear in the spectrum with the difference being their proportion. In one unpainted spot, the quantity of copper is bigger than lead, while in the rest the trend is the opposite. However, XRMC also allowed to provide some compositional data (Table 3).

Noteworthy is also the fact that through the MC simulation, little bromine was detected in the red spot. The fact could be explained as a possible clue to methyl bromide, that was said to be used in the past as fumigant pesticides [92] (Fig. 6, red spot). 


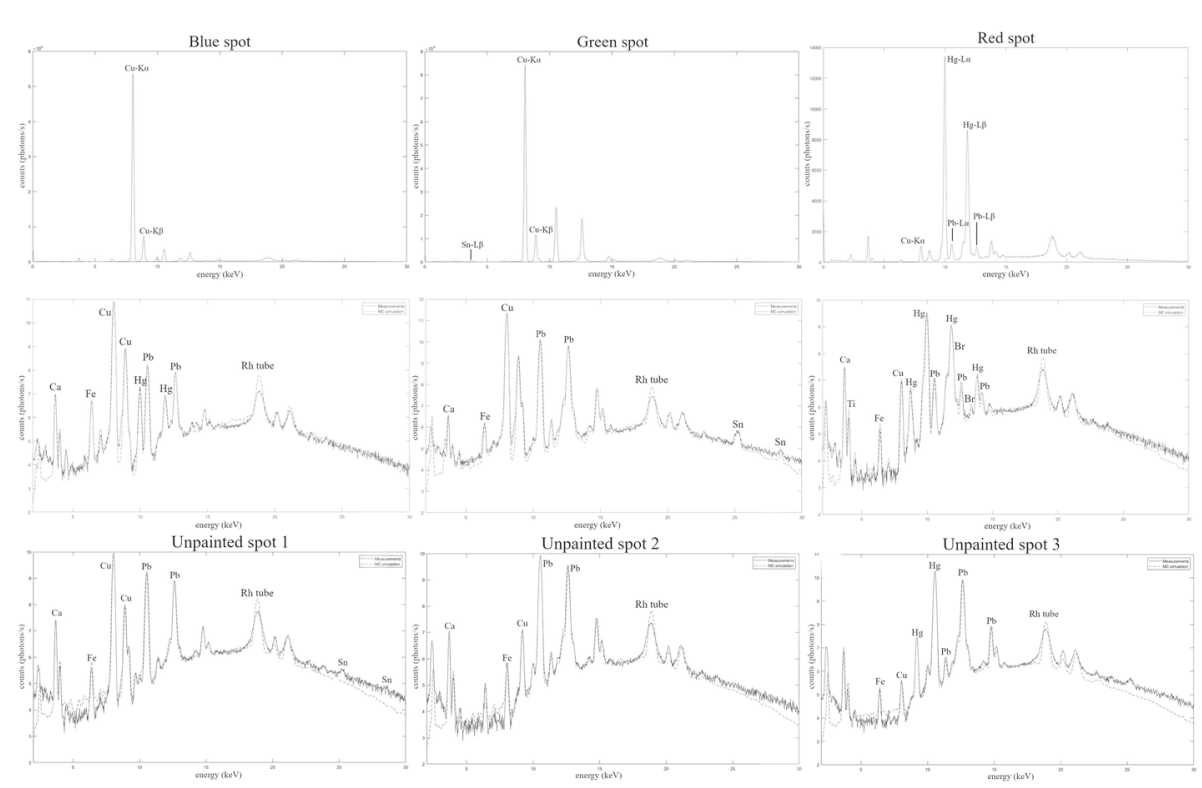

Fig. 6 p-XRF spectra vs Monte Carlo simulations. On the first two rows, representative spectra for each coloured area are presented in linear scale of ordinate (first row) and logarithmic scale of ordinate (second row) with the main peaks marked with labels. On the second row, the same p-XRF spectra (solid line) are presented against the respective Monte Carlo simulations (dotted line) in logarithmic scale of ordinate. On the final row, MC simulations are presented against real measurements

As for the calculated level of thickness (Table 3), the XRMC software computed various levels comprised in the range $20-40 \mu \mathrm{m}$ for all layers: coloured paints, printing inks below the paints (of the three-layer model) and uncovered inks (of the two-layer model). Therefore, these results are comparable, they consistently fall in a similar range and are supported by the analysis on micro-samples from the other leaves. The SEM images of small samples of printing inks, as well as green and red paints (fols. $11 \mathrm{r}$ and $47 \mathrm{v}$ ) reveal indeed a range of 32-38 $\mu \mathrm{m}$ for the uncovered ink layer, 23-34 $\mu \mathrm{m}$ for the green paint and 32-47 $\mu \mathrm{m}$ for the red paint (no good reference for the sample for the blue paint was available). At an overall consideration, the extreme range for all pictorial layers from the SEM images is $23-47 \mu \mathrm{m}$, which is consistent with the range proposed through the $\mathrm{MC}$ simulations. The range obtained through the MC simulations is slightly broadened when the large uncertainty is considered and extends to $10-50 \mu \mathrm{m}$, but it is still compatible with the reference values $(23-47 \mu \mathrm{m}$, SEM images).

\subsection{Chemical characterisation versus Monte Carlo simulations}

XRMC showed the stratigraphic profiles of copper and lead from the printing ink layers as consistent throughout the analysed leaf, both in the simulated two-layer models and the threelayer models. Indeed, the average amount of lead beneath the pictorial layers and an unpainted spot approximates $0.60 \%$ (calculated range $0.60-0.62 \%$ ) and copper falls similarly in the range $0.05-0.40 \%$ (Table 3 ), even with being slightly more abundant when overlaid with colour paints. 


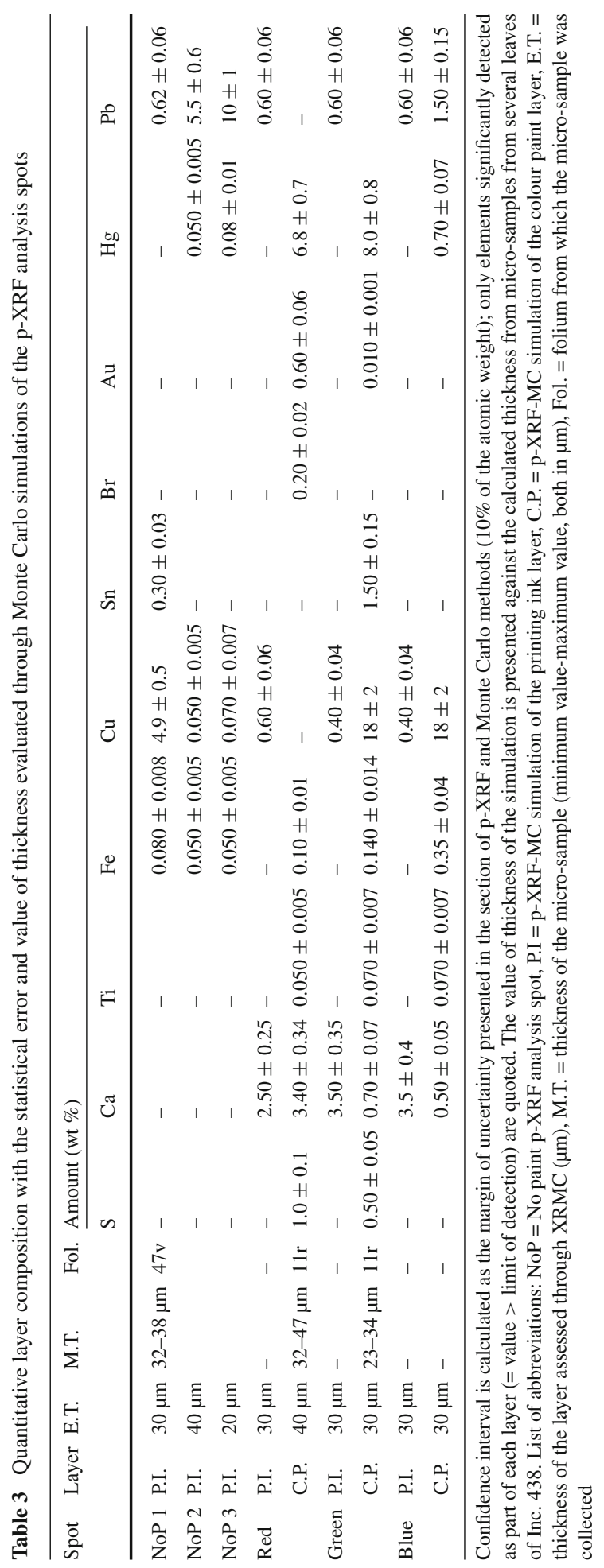




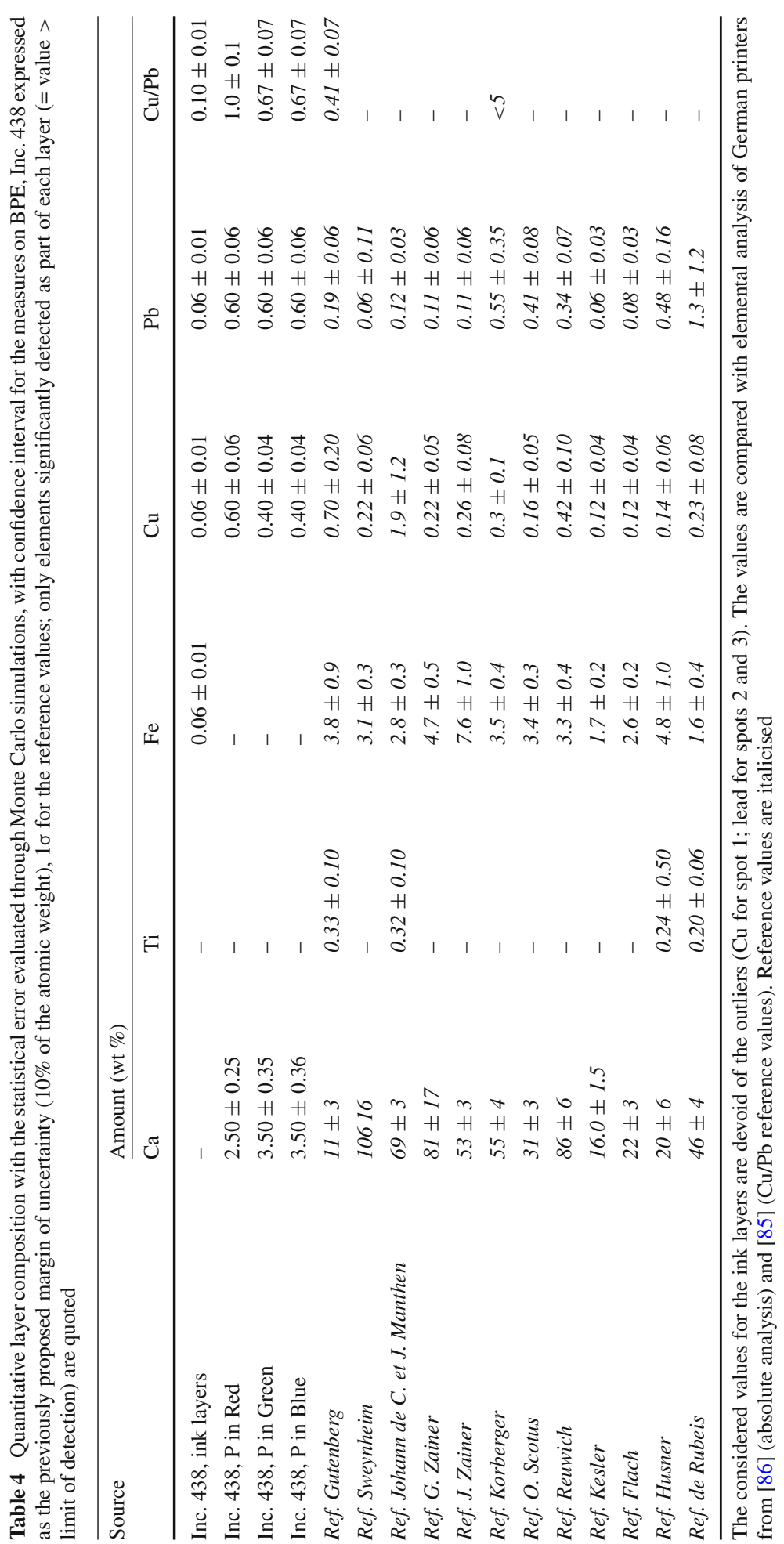


Some differences exist, however, between copper and lead across the unpainted spots. Spot 1 is significantly richer in copper than the other; instead, spots 2 and 3 contain a greater quantity of lead than the other. To elucidate the arising dissimilarity, the images of the spots taken with the built-in camera constitute a valid aid for data validation: the first image of spot 1 displays, indeed, green regions at the periphery of the spot. Looking closely at the p-XRF spectrum (Fig. 6), little tin also appears. The increased dose of copper and of tin together is a good piece of evidence to suppose that residual green pigment (made of the mixture of malachite and lead tin yellow I) stayed trapped into the collagen fibres of the parchment substrate. The images of the remaining spots 2 and 3 also reveal a similar condition in which a reddish paint covers scattered areas of the spot. This fact considered together with the detected mercury in these two spots, might rightfully allow to interpret the red substance as residual red pigment that stayed equally attached to the substrate. Aside tracking vestigial paints, the variation of lead over spots 2 and 3 appears significant.

Such a difference can be explained through visual assessment: the printed design of spot 3 appears more visually bleached than the other, in most likelihood due to the stronger hiding power of a covering paint. As for the materials that could explain the increased paints opacity, the table presenting the elemental quantification from XRMC refers that the bulk of both lead and mercury of spot 3 is larger than spot 2. Accordingly, spot 3 could lay in an area having more red paint.

XRMC allowed to draw further information with regard to the exact mapping of some elements across the ink layer, both within the two-layer models and the three-layer models. This is the case of lead, whose amounts as calculated with XRMC of lead in the ink layers are actually a sum of the elements from the first layer (that is the parchment ground) and the ink layers. The fact is elucidated through the unpainted spot 1: the $0.62 \%$ of this ink layer is made up with $0.33 \%$ of lead from the layer beneath. Since the technical research of the latemedieval-to-Renaissance manufacture of parchment does not report lead-based compounds in its manufacture, this amount could be more reasonably attributed to the printing inks on the rear side of the same leaf. This fact would allow to distribute comparable quantities of lead not only across the leaf, but also on the two sides of the printed page. On the contrary, these claims have been dismissed because simulations of a more complex structure with a higher number of layers (3 layers) of similar composition were done but no evidence or improvements in the simulated spectra have been observed.

Further relevant information that XRMC allowed to extract results regards the major stratigraphic parameters at the core of this research, namely the calculated valued of thickness. Unless one case (unpainted spot 3), they generally fall in the ranges suggested by the SEM analyses of micro-samples collected from other leaves of BPE, Inc. 438 (Table 3).

These compositional data are of historical relevance. When the amount of copper and lead are expressed as their ratios $(\mathrm{Cu} / \mathrm{Pb})$, they agree with previous non-destructive analyses of printing inks from German printers $[85,86]$, but also when expressed as absolute concentrations (Table 4). The concentration of calcium was also interesting, for it appeared significantly higher only in the three-layer model with a range between 2.5 and $3.5 \%$ (wt).

These compositional data could also be affected by the superimposition of the layers of paint as previously specified: Table 1 shows that the amount of coloured paints in the spots fell in the range 49-60\% of the whole area or that there was a significant influence from surrounding coloured areas (4-18\%). It follows that the elemental quantification for those layers cannot be regarded as exact. Also, this model generally makes good prediction of the values of thickness but one case: it fails to determine the exact depth in a two-layer model of the printing ink, namely unpainted spot 3 (Table 3). 
Therefore, XRMC could provide useful compositional data. This approach allowed to retrieve interesting information: on a historical level, it confirmed the same intentional supplement of lead and copper to the formulation of printing ink of the German typography; on a practical level, it shows that the ink layer contains elements of a sufficient $Z$ to encourage further research. In the next steps, laboratory reproductions could be prepared to explore at a deeper level this condition together with other analytical conditions than used to build a reliable protocol for thickness assessment in illumination analyses.

\section{Conclusions}

The present paper provides, for the first time, the exploratory application of MC simulations for the stratigraphic evaluation of paints in illuminated books. The painted illustration consisted of a printed design over-coloured with opaque paints. MC simulations were computed with the aim of evaluating the thickness; the elemental composition of the detectable elements of pictorial bi-layers was used as the main parameter of data validation next to the comparison with data previously acquired for an illuminated early printed book, the BPE Inc. 438. Analytical data from a previous characterisation of the same item (paints components, $\mathrm{P} / \mathrm{M}$ ratio) were used to feed models for the elaboration of MC simulations of $\mathrm{p}$-XRF spectra of chosen analysis spots through XRMC. For the evaluation, multiple analysis spots were appointed for each coloured paints - red, green and blue - and for unpainted areas. XRMC simulated two models, a three-layer model for the painted areas and a two-layer model for the unpainted area. In three-layer models, the extent of the pictorial areas conditioned severely the choice and outcome of the evaluation; in two-layer models, the presence of coloured paints in the analysis spot influenced the overall composition. Despite of limitations, the methodology allowed to successfully detect the thickness for the paints while providing insightful details of historical and technical meaning around the elemental composition of the analysed areas.

This method pioneered thickness assessments for an unexplored class of pictorial coatings, that are non-metallic layers. At the same time, the applied MC-XRF method provided elemental distributions, expressed as $\mathrm{Pb}$ and $\mathrm{Cu}$ alone and as ratios, alone and contextually to overlying coloured paints. These results have important historical significance because of providing insights into the technological use of lead (and possibly copper) in the manufacture of the fatty media for printing: an intentional supplement of these materials sourced from mineral oxides has been well documented in media for painting, less scarcely in inks formulated in Germany, while it has never been proved in sixteenth-century French prints before.

Next to the innovative knowledge, the results from the applied method were even more impressive because they proved to be comparable with those obtained with such high precision techniques as $\mu$-SR-XRF and PIXE $[85,86]$ by working instead on data from an in situ, lowenergy XRF system.

These results also offered further layers of interpretation. Although high-resolution XRF systems are generally preferred to minimise the undesired influence of neighbouring areas, the pictorial extent for most of the analysis spots was sufficiently broad to obtain workable data. This fact was also even more remarkable, given the potential obstacle of very diluted layers of paint of BPE, Inc. 438. The roughness of the surface was analytically measured and also simulated in XRMC. As a result, probably due to the focal spot size and the geometry of the p-XRF analyser, the use of a simple flat surface model in the Monte Carlo simulation does not introduce any detectable modification in the simulated spectrum. Future studies will 
investigate the best sensible compromise between spot aperture and extension of coloured areas to define smaller analysis spots.

In summary, the remarkable results from the application of the XRF-MC protocol on book decoration invited further exploration to elaborate a protocol for the investigation of a broader cluster of cases on books paintings.

Acknowledgements The research was supported by the Portuguese Foundation for Science and Technology (FCT) by National Funds under the projects UIDP/04449/2020 (HERCULES Laboratory), DL 57/2016/CP1372/CT0012 (Norma Transitória), UIDB/00057/2020 (CIDEHUS/UE) and UIDB/04042/2020 (CIEBA/UL). The authors express their gratitude to the Public Library of Évora for authorising the analysis on BPE, Inc. 438 and making the item available for the study. Silvia Bottura Scardina thanks personally the University of Lisbon to allow the present study through the financial support of the research grant BD-2017.

\section{Declarations}

Funding This study was funded by DL 57/2016/CP1372/CT0012 (Norma Transitória), UIDP/04449/2020 (HERCULES Laboratory) and BD-2017 (Grant for doctoral studies).

Conflict of interest Antonio Brunetti, Carlo Bottaini and Catarina Miguel certify that they have no affiliation or involvement in any organisation or entity with any financial interest, or non-financial interest in the subject matter or materials discussed in this manuscript. Silvia Bottura Scardina certifies the involvement in the University of Lisbon for the attribution of the Ph.D. grant as the financial support of the project "The Technique of Illumination in the sixteenth-century Book of Hours-a Multidisciplinary Study of the Materials, Technique and Artistic Influences in Hardouyns' Incunabula"

Data availability Data are available on request from the authors.

Author contributions $\mathrm{CB}$ planned and performed the p-XRF analysis; $\mathrm{AB}$ designed the MC model, the computational framework and carried out the MC simulations. SBS and CM interpreted the compositional data on the paints, and with $\mathrm{AB}$ analysed the data from the MC simulations. SBS wrote the manuscript with input from all authors. CB and CM conceived the study and SBS was in charge of overall direction.

\section{References}

1. R. Johnston-Feller, Color Science in the Examination of Museum Objects, 1st edn. (Getty Publications, Los Angeles, 2001), pp. 15-98

2. J. Dong et al., Sci. Rep. (2018). https://doi.org/10.1038/s41598-017-15069-2

3. M. Gil et al., Xray Spectrom. (2008). https://doi.org/10.1002/xrs.1024

4. L. Brizi et al., Magn. Reson. Chem. (2020). https://doi.org/10.1002/mrc.5054

5. S. Prati et al., Anal. Bioanal. Chem. (2013). https://doi.org/10.1007/s00216-012-6435-3

6. S. Prati et al., Appl. Phys. A (2016). https://doi.org/10.1007/s41061-016-0025-3

7. M. Clarke, Stud. Conserv. (2001). https://doi.org/10.1179/sic.2001.46.Supplement-1.3

8. A.N. Shugar, J.L. Mass, Handheld XRF for Art and Archaeology (Leuven University Press, Leuven, 2012)

9. R.H. Tykot, Appl. Spectrosc. (2016). https://doi.org/10.1177/0003702815616745

10. L. Bonizzoni et al., Appl. Phys. A (2007). https://doi.org/10.1007/s00339-008-4482-6

11. L. Bonizzoni et al., Xray Spectrom. (2008). https://doi.org/10.1002/xrs.930

12. S. Pessanha et al., Xray Spectrom. (2014). https://doi.org/10.1002/xrs.2518

13. R.P. Gardner, J.M. Doster, X-Ray Spectrom. (1982). https://doi.org/10.1002/xrs. 1300110409

14. R.P. Gardner, J.M. Doster, X-Ray Spectrom. (1982). https://doi.org/10.1002/xrs. 1300110410

15. J.E. Fernandez, Comput. Phys. Commun. (1989). https://doi.org/10.1016/0010-4655(89)90083-0

16. T. Schoonjans et al., Spectrochim. Acta Part B (2012). https://doi.org/10.1016/j.sab.2012.03.011

17. V. Scot et al., Nucl. Instrum. Methods Phys. Res. B (2007). https://doi.org/10.1016/j.nimb.2007.04.205

18. J. Baro et al., Nucl. Instrum. Methods Phys. Res. Sect. B (1995). https://doi.org/10.1016/0168$583 \mathrm{X}(95) 00349-5$

19. X. Llovet et al., Surf. Interface Anal. (2005). https://doi.org/10.1002/sia.2096 
20. S. Agostinelli et al., Nucl. Instrum. Methods Phys. Res. Sect. A (2003). https://doi.org/10.1016/S01689002(03)01368-8

21. S. Guatelli et al., IEEE Trans. Nucl. Sci. (2007). https://doi.org/10.1109/TNS.2007.896214

22. J. Hendricks et al., Appl. Radiat. Isot. (2000). https://doi.org/10.1016/S0969-8043(00)00231-1

23. T. Schoonjans et al., Spectrochim. Acta B (2013). https://doi.org/10.1016/j.sab.2012.12.011

24. L. Vincze et al., Spectrochim. Acta B (1993). https://doi.org/10.1016/0584-8547(93)80060-8

25. L. Vincze et al., Spectrochim. Acta B (1995). https://doi.org/10.1016/0584-8547(95)01361-X

26. L. Vincze et al., Spectrochim. Acta B (1999). https://doi.org/10.1016/S0584-8547(99)00094-4

27. U. Bottigli et al., Spectrochim. Acta B (2004). https://doi.org/10.1016/j.sab.2004.03.016

28. B. Golosio et al., Comput. Phys. Commun. (2014). https://doi.org/10.1016/j.cpc.2013.10.034

29. T. Schoonjans et al., Spectrochim. Acta Part B (2011). https://doi.org/10.1016/j.sab.2011.09.011

30. A. Brunetti et al., At. Spectrosc. Spectrochim. Acta Part B (2015). https://doi.org/10.1016/j.sab.2015.03. 014

31. W. Giurlani et al., Coatings (2019). https://doi.org/10.3390/coatings 9020079

32. L. Angeli et al., J. Archaeol. Sci. Rep. (2019). https://doi.org/10.1016/j.jasrep.2019.01.008

33. C. Bottaini et al., Spectrochim. Acta B (2015). https://doi.org/10.1016/j.sab.2014.10.015

34. C. Bottaini et al., Appl. Spectr. (2018). https://doi.org/10.1177/0003702817721934

35. C. Bottaini et al., Archaeol. Anthropol. Sci. (2018). https://doi.org/10.1007/s12520-017-0501-x

36. C. Bottaini et al., Eur. Phys. J. Plus (2019). https://doi.org/10.1140/epjp/i2019-12894-4

37. S. Pessanha et al., Spectrochim. Acta Part B At. Spectrosc. (2019). https://doi.org/10.1016/j.sab.2019.04. 006

38. M. Alfeld et al., J. Anal. At. Spectrom. (2011). https://doi.org/10.1039/C0JA00257G

39. M. Alfeld et al., J. Anal. At. Spectrom. (2013). https://doi.org/10.1039/C3JA30341A

40. M. Alfeld et al., Appl. Phys. A (2013). https://doi.org/10.1007/s00339-012-7526-X

41. A.T. da Silva et al., Herit. Sci. (2017). https://doi.org/10.1186/s40494-017-0150-5

42. F.P. Romano et al., J. Anal. At. Spectrom. (2017). https://doi.org/10.1039/C6JA00439C

43. S. Saverwyns et al., Microchem. J. (2018). https://doi.org/10.1016/j.microc.2017.10.008

44. S. Lins et al., Res. J. Appl. Sc. (2020). https://doi.org/10.3390/app10103582

45. S. Lins et al., Front. Chem. (2020). https://doi.org/10.3389/fchem.2020.00175

46. C. Miguel et al., J. Raman Spectrosc. (2009). https://doi.org/10.1002/jrs.2350Citations:38

47. L. de Viguerie et al., Herit. Sci. (2018). https://doi.org/10.1186/s40494-018-0177-1

48. P. Ricciardi et al., Microchem. J. (2016). https://doi.org/10.1016/j.microc.2015.10.020

49. W. Faubel et al., Spectrochim. Acta Part B (2007). https://doi.org/10.1016/j.sab.2007.03.029

50. M. Manso et al., Appl. Phys. A (2015). https://doi.org/10.1007/s00339-014-8924-Z

51. S. Legrand et al., Microchem. J. (2018). https://doi.org/10.1016/j.microc.2018.01.001

52. G.I. Serhrouchni et al., Eur. Phys. J. Plus (2019). https://doi.org/10.1140/epjp/i2019-12896-2

53. S. Pessanha et al., Spectrochim. Acta Part B (2018). https://doi.org/10.1016/j.sab.2018.04.021

54. D.V. Thompson, The Materials and Techniques of Medieval Painting, 2nd edn. (Dover Publications, New York, 1956)

55. P. Renouard, J. Veyrin-Forrer, B. Moreau, Brigitte, Répertoire Des Imprimeurs Parisiens, 1st edn. (ParisAbbeville, Imprimerie F. Paillart, 1965), pp. 197-198

56. J. Müller, Dictionnaire Abrégé Des Imprimeurs, 1st edn. (Heitz, Paris, 1970), p. 76

57. M.B. Winn, Papers. Bibliographical Society of. America 103, 2 (2009)

58. H. Tenschert, I. Nettekoven, C. Zöhl, Horae BMV, 1st edn. (Antiquariat Bibermühle, Ramsen, 2003-2015)

59. I. Cid, Incunábulos da Biblioteca Pública e Arquivo Distrital de Évora(Biblioteca e Arquivo Distrital, Évora, 1988)

60. M.-L. Polain, Marques des imprimeurs, 1st edn. (Slatkine, Paris, 1926), no. 103

61. P. Renouard, Les Marques Typographiques Parisiennes (Champion, Paris, 1928), pp. 134-135

62. I. Nettekoven, Der Meister Der Apokalypsenrose Der Saint Chapelle (Brepols, Turnhout, 2004), p. 534

63. C. Miguel et al., J. Cul. Herit. (2019). https://doi.org/10.1016/j.culher.2019.05.014

64. S. Bottura Scardina et al., Ge-conservación (2020). https://doi.org/10.37558/gec.v18i1.825

65. C. Tibúrcio et al., Microchem. J. (2020). https://doi.org/10.1016/j.microc.2019.104455

66. A. Brunetti et al., Spectrochim. Acta Part B At. Spectrosc. (2004). https://doi.org/10.1016/j.sab.2004.03. 014

67. T. He et al., Nucl. Instrum. Methods Phys. Res. (1990). https://doi.org/10.1016/0168-9002(90)90805-G

68. E. Tomasini, G. Siracusano, M.S. Maier, Microchem. J. (2012). https://doi.org/10.1016/j.microc.2011. 11.005

69. M.E. Fleet, Biomaterials (2009). https://doi.org/10.1016/j.biomaterials.2008.12.007

70. B.R. Singh et al., Proc. SPIE Biomol. Spectroscopy (1993). https://doi.org/10.1117/12.145242

71. V. Balan et al., Materials (2019). https://doi.org/10.3390/ma12182884 
72. N. Kourkoumelis et al., Clin. Rev. Bone Miner. Metab. (2019). https://doi.org/10.1007/s12018-018-9255$\mathrm{y}$

73. A. Schönemann, H.G. Edwards, Anal. Bioanal. Chem. (2011). https://doi.org/10.1007/2Fs00216-0114855-0

74. R.J. Meilunas, J.G. Bentsen, A. Steinberg, Stud. Conserv. (1990). https://doi.org/10.1179/sic.1990.35.1. 33

75. M. Lazzari, O. Chiantore, Oscar Polym. Degrad. Stab. (1999). https://doi.org/10.1016/S01413910(99)00020-8

76. J. Mallégol, J.-L. Gardette, J. Lemaire, J. Am. Oil Chem. Soc. (2000). https://doi.org/10.1007/s11746000-0042-4

77. I.A. Balakhnina et al., J. Appl. Spectr. (2011). https://doi.org/10.1007/s10812-011-9444-7

78. J.D. van Den Berg et al., J. Sep. Sci. (2004). https://doi.org/10.1002/jssc.200301610

79. S. Boyatzis, E. Ioakimoglou, P. Argitis, J. Appl. Polym. (2002). https://doi.org/10.1002/app.10117

80. Z.O. Oyman, W. Ming, R.R. van der Linde, Prog. Org. Coat. (2005). https://doi.org/10.1016/j.porgcoat. 2005.06.004

81. L. De Viguerie et al., Prog. Org. Coat. (2016). https://doi.org/10.1016/j.porgcoat.2015.12.010

82. G. Ruscelli, Secreti del Reverendo Donno Alessio Piemontese (Venezia, 1555)

83. A. Stijnman, Engraving and Etching (Brill-Hes \& De Graaf, London, 2012)

84. D. Scalarone, M. Lazzari, O. Chiantore, J. Anal. Appl. Pyrolysis (2002). https://doi.org/10.1007/s00216016-9772-9

85. T.A. Cahill et al., Archaeometry (1984). https://doi.org/10.1111/j.1475-4754.1984.tb00312.x

86. H. Mommsen et al., Archaeometry (1996). https://doi.org/10.1111/j.1475-4754.1996.tb00782.x

87. C.S. Tumosa, M.F. Mecklenburg, Stud. Conserv. (2005). https://doi.org/10.1179/sic.2005.50. Supplement- 1.39

88. B.Z. Juita, E.M. Kennedy, J.C. Mackie, Fire Sci. Rev. (2012). https://doi.org/10.1186/2193-0414-1-3

89. C. Miguel et al., Chemom. Intell. Lab. Syst. (2012). https://doi.org/10.1016/j.chemolab.2012.09.003

90. S.M. Rousu et al., In Printing and Graphic Arts Conference (TAPPI Press, Atlanta, 2000), pp. 55-70

91. B. Lemière, J. Geochem. Explor. (2018). https://doi.org/10.1016/j.gexplo.2018.02.006

92. H.M. Szczepanowska, Conservation of Cultural Heritage: Key Principles and Approaches (Routledge, London-New York, 2013), p. 40 